\section{Tripletherapie erhöht Heilungschancen bei Hörsturz}

Bei einem idiopathischen Hörsturz kann eine Kombinationstherapie aus Steroiden, Carbogen-Inhalation und Lipo-PGE1 besser helfen als Steroide alleine oder Steroide plus Carbogen. Das hat eine südkoreanische Studie ergeben, die alle drei Therapien an einer Stichprobe von 670 Probanden verglich.

$\mathrm{D}$ ie Wissenschaftler aus Südkorea schlossen in die Studie bisher unbehandelte Probanden mit unilateralem idiopathischen Hörverlust ein und behandelten sie stationär mit verschiedenen Medikamentenkombinationen: Die D-Gruppe $(\mathrm{n}=270)$ erhielt eine intravenöse Monotherapie mit Steroiden, die DC-Gruppe Steroide und Carbogen-Inhalation ( $\mathrm{n}=194)$ und die DCP-Gruppe $(\mathrm{n}=200)$ Steroide, Carbogen-Inhalation und Lipoprostaglandin-Infusionen.

Die Steroidtherapie beinhaltete eine zweimal täglich verabreichte Dexamethason-Infusion (20 mg). Bei der CarbogenTherapie inhalierten die Probanden achtmal täglich für 30 Minuten $95 \% \mathrm{O}_{2}$ und $5 \% \mathrm{CO}_{2}$. Die Lipo-PGE1-Behandlung bestand aus täglichen Infusionen mit $10 \mu \mathrm{L}$ Lipo-PGE1.

Gemessen wurden die Ergebnisse mithilfe einer Reintonaudiometrie, während des sieben Tage dauernden Krankenhausaufenthaltes täglich und erneut zwei Monate nach dem Hörsturz. Die höchsten Heilungsraten wies mit $67,0 \%$ die Patientengruppe mit der Tripletherapie auf im Vergleich zu den Gesamtheilungsraten von $57,5 \%$. Heilung definierten die Wissenschaftler als Verbesserung des Hörvermögens im Sinne der Siegel-Kriterien eins bis drei.

Dabei profitierten nur die Patienten von der Tripletherapie, die jünger als 50
Jahre alt waren, innerhalb einer Woche behandelt wurden und einen initialen Hörverlust unter $90 \mathrm{~dB}$ hatten. Bei älteren Patienten, einem späteren Behandlungsbeginn und einem größeren Hörverlust brachte die Tripletherapie keinen Vorteil gegenüber der Monotherapie mit Steroiden oder der Kombinationstherapie aus Steroiden und Carbogen. In Bezug auf die Begleitsymptome eines Hörsturzes zeigten sich nur bei Tinnitus signifikante Verbesserungen.

Fazit: Unter 50-jährige Patienten, die an einem Hörsturz mit initialem Hörverlust von weniger als $90 \mathrm{~dB}$ erkranken und innerhalb einer Woche behandelt werden, erholen sich mit einer höheren Wahrscheinlichkeit von ihrer Erkrankung, wenn sie sich einer Kombinationstherapie mit Steroiden, Carbogen und Lipo-PGE1 unterziehen.

Heike Grosse

Kim MG et al. Effect of steroid, carbogen inhalation, and lipoprostaglandin E1 combination therapy for sudden sensorineural hearing loss. Am J Otolaryngol 2011; 32: 91-5

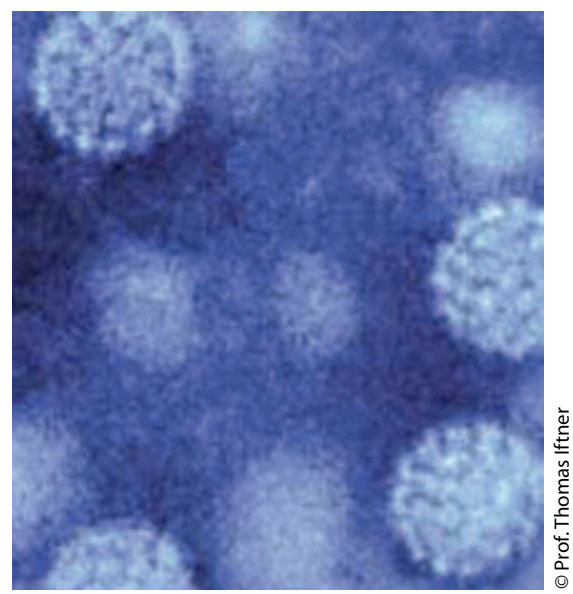

HPV wurde wiederholt auch in Nasopharynx-Karzinomen nachgewiesen.

folgende Schlüsse:

1. Bei Nasopharynx-Karzinomen ist EBV offenbar nicht das einzige auslösende Agens.

2. Die ätiologische Bedeutung von HPV ist aufgrund von PCR-Studien wahrscheinlich überbewertet worden.

3. Viele, wenn nicht sogar alle Karzinome, die den Nasopharynx mitbetreffen und in denen HPV vorkommt, sind wahrscheinlich primär Karzinome des Oropharynx. Beate Schumacher

Singhi AD et al. High risk human papillomavirus in nasopharyngeal carcinoma. Head Neck 2011 Apr 11 